\title{
" Astral characters of kingship in the Sasanian and Byzantine worlds ». La Persia e Bisanzio. Atti dei convegni Lincei (Roma), 201, 2004, pp. 555-594.
}

\section{Frantz Grenet}

\section{(2) OpenEdition}

1 Journals

\section{Édition électronique}

URL : http://journals.openedition.org/abstractairanica/11852

DOI : 10.4000/abstractairanica. 11852

ISSN : 1961-960X

Éditeur :

CNRS (UMR 7528 Mondes iraniens et indiens), Éditions de l'IFRI

\section{Édition imprimée}

Date de publication : 15 mai 2007

ISSN : 0240-8910

\section{Référence électronique}

Frantz Grenet, « «Astral characters of kingship in the Sasanian and Byzantine worlds ». La Persia e Bisanzio. Atti dei convegni Lincei (Roma), 201, 2004, pp. 555-594. », Abstracta Iranica [En ligne], Volume 28 | 2007, document 243, mis en ligne le 18 septembre 2007, consulté le 25 septembre 2020. URL : http://journals.openedition.org/abstractairanica/11852 ; DOI : https://doi.org/10.4000/ abstractairanica. 11852

Ce document a été généré automatiquement le 25 septembre 2020

Tous droits réservés 
« Astral characters of kingship in the Sasanian and Byzantine worlds ». La Persia e Bisanzio. Atti dei convegni Lincei (Roma), 201, 2004, pp. 555-594.

Frantz Grenet 
1 A la faveur d'une approche comparée des symboliques sassanides et byzantine de la royauté, dont les correspondances diplomatiques montrent que les deux parties percevaient très bien la profonde analogie, A. Panaino revisite certaines notions fondamentales du vocabulaire sassanide. Bay est à prendre au sens de "seigneur », avec une rémanence du sens étymologique "extraordinary giver »; la traduction grecque theos est à prendre comme "the middle point between bay and divus", mais les Sassanides n'ont pas adopté la notion de divinisation post-mortem que ce dernier terme implique. $K \bar{e}$ čihr az yazadān doit se comprendre non pas «qui est de la race des dieux ", mais «qui a l'aspect des dieux» (ce qui rejoint les conclusions tirées un peu auparavant par A. Soudovar, The aura of kings, 2003, pp. 41-48). L'argument vraiment décisif est fourni par la lettre de Khosrow I ${ }^{\text {er }}$ à Justinien, dans la version grecque de Ménandre qui dit explicitement avoir recouru à un mot à mot: l'expression en discussion est traduite hos ék théôn charaktèrizetai " qui est formé à l'image des dieux " (ici et pour les autres titres Panaino renvoie à Ph. Huyse, "Die sasanidische Königstitulatur : Eine Gegenberstellung der Quellen », depuis paru dans J. Wiesehöfer, Ph. Huyse (eds.), Ėrān ud Anērān, München, 2006). Dans ce contexte l'assimilation métaphorique du roi aux luminaires, dont divers exemples littéraires et iconographiques sont analysés, s'explique par l'idée que leur xwarrah est de même nature que le leur (et non, comme les Grecs et les Romains l'ont parfois cru, par le fait qu'ils se considéraient comme des dieux).

INDEX

Thèmes : 6.1. Zoroastrisme

\section{AUTEURS}

FRANTZ GRENET

CNRS - EPHE - Paris 